\title{
Management of Non-contiguous Vertebral Fractures
}

\author{
D. S. Tearse, M.D., J. S. Keene, M.D., D. S. Drummond, M.D.
}

University of Wisconsin, Spinal Injury Center, Madison, Wisconsin, U.S.A.

\begin{abstract}
Summary
Non-contiguous vertebral fractures are not common. In 78 consecutive patients with acute thoracolumbar fractures, we found that 13 patients $\left(16 \cdot 7^{\circ}{ }_{0}\right)$ had noncontiguous spinal injuries. Five patients had a combination of cervical and thoracolumbar injuries and eight had a combination of thoracic and lumbar injuries. Four of the eight patients in the thoracic and lumbar group had posterior surgical stabilisation procedures. Two patients had instrumentation of all injured, noncontiguous vertebrae and healing occurred uneventfully, and two patients had instrumentation of only the major fracture and a progressive deformity occurred at the site of the minor fracture. We concluded that: (1) patients with a spinal fracture should have radiographic evaluation of their entire spine to rule out non-contiguous fractures; (2) if non-contiguous fractures are evident on standard radiographs, all levels of injury should be evaluated with computerised tomography; and (3) all unstable or potentially unstable injuries should be reduced, stabilised, and fused.
\end{abstract}

Key words: Non-contiguous fractures; Acute spine injury.

\section{Introduction}

Although many studies discuss the evaluation and management of vertebral fractures involving one segment of the spine, only a few reports comment on the incidence of spinal fractures occurring at several levels. Griffith (1966) found a $3 \cdot 2^{\circ}$ incidence of non-contiguous injuries in a series of 155 thoracolumbar fractures. Calenoff (1978) reported a $4 \cdot 5^{\circ}{ }_{0}$ incidence of non-contiguous vertebral injuries in a series of 385 patients with spinal cord injuries. He noted that the delay in diagnosis of non-contiguous fractures averaged 53 days. It is apparent from these studies that a second or third level of injury to the spine is often not diagnosed. Similarly, the management and results of treatment of these non-contiguous injuries has not been reported previously. 


\section{Materials and methods}

Seventy-eight consecutive patients with acute thoracolumbar fractures admitted to the University of Wisconsin Hospital are the basis of this report. Patients with non-contiguous fractures (two fractures separated by a normal segment of the spine) were identified from a review of radiographs obtained at the time of the initial injury.

The major level of injury was defined as the fracture or fracture-dislocation that: (1) appeared most unstable on the standard radiographs and CT scans; or (2) was associated with a neurological deficit. The minor level of injury was stable by radiographic criteria and was not associated with a neurological lesion. The type of injury, per cent of anterior vertebral body compression, angle of deformity, and displacement percentage were determined for all levels of injury. The per cent of anterior vertebral body compression was determined in the following manner. First, the height of the anterior surface of the vertebra above and below the compressed vertebra were measured to establish the expected height of the fractured vertebra. If contiguous vertebrae were also compressed, several vertebra above and below the fractured vertebra were measured to establish the expected height. Second, the anterior height of the compressed vertebra was measured and this value was subtracted from the expected height of that vertebra. Third, the difference between the expected height and actual height was divided by the expected height and multiplied by 100 .

Angular deformity and the displacement percentage were determined by the method described by Dickson (1978). With this method of measurement, the angle of deformity is the angle created at the intersection of lines drawn along the posterior surfaces of the vertebral bodies above and below the fractured vertebra. The displacement percentage was the distance between vertical lines drawn along the posterior surface of the superior vertebral body and the posterior surface of the fractured vertebra divided by the anterior-posterior width of the normal vertebra immediately below the fractured one. By measuring anterior compression, angle of deformity, and displacement percentage in this manner, any differences in magnification between the initial and follow-up radiographs were nullified. Similarly, the overall anatomical results were determined by calculating and comparing the percentage of the initial deformity with that observed on subsequent radiographs. This method of analysing the results, as described by Bradford (1977), nullifies the bias introduced by spines with small initial deformities.

\section{Results}

Thirteen $\left(16 \cdot 7^{\circ}{ }_{0}\right)$ of the 78 patients reviewed had non-contiguous fractures. The types of fractures, levels of injury and treatment of these thirteen patients are summarised in Table I. Eleven patients were male and two were female. Ages ranged from 18 to 70 years (median 21.5, mean 28.7). Eight patients were injured in motor vehicle accidents, three in falls from heights, and two from other causes. The thirteen non-contiguous fractures were a combination of thoracic and lumbar injuries in eight patients (Cases 6-13), and a combination of cervical and thoracolumbar injuries in five patients (Cases 1-5). The major 
Table I The Levels of Injury, Types of Fractures, and Method Treatment for the Thirteen Patients with Non-contiguous Fractures

\begin{tabular}{|c|c|c|c|c|c|c|c|}
\hline Case & Age & Cause & $\begin{array}{l}\text { Major } \\
\text { level }\end{array}$ & $\begin{array}{l}\text { Type of } \\
\text { fracture }\end{array}$ & $\begin{array}{l}\text { Minor } \\
\text { level }\end{array}$ & $\begin{array}{l}\text { Type of } \\
\text { fracture }\end{array}$ & Treatment \\
\hline 1 & 22 & MVA & T5-6 & Fx-disloc. & $\mathrm{C} 2$ & Compression & $\begin{array}{l}\text { Distraction rods } \\
\text { (T2-9) }\end{array}$ \\
\hline 2 & 21 & MVA & L3-4 & Flex-dist. & C6 & Compression & $\begin{array}{l}\text { Compression rods } \\
\text { (L2-5) }\end{array}$ \\
\hline 3 & 18 & MVA & $\mathrm{T} 11-12$ & Flex-dist. & $\mathrm{C} 6-7$ & Subluxation & Non-operative \\
\hline 4 & 23 & MVA & $\mathrm{L} 2$ & Burst & $\mathrm{C} 2$ & Spinous process & $\begin{array}{l}\text { Distraction rods } \\
\text { (T10-L5) }\end{array}$ \\
\hline 5 & 25 & Assault & $\mathrm{T} 8$ & Burst & $\mathrm{C} 5$ & Tear-drop & Non-operative \\
\hline 6 & 33 & MVA & L4 & Burst & $\mathrm{Ll}_{1}$ & Compression & Non-operative \\
\hline 7 & 70 & Fall & $\mathrm{T} 10$ & Burst & L2 & Compression & Non-operative \\
\hline 8 & 21 & Fall & L4 & Burst & $\mathrm{L} 2$ & Compression & $\begin{array}{l}\text { Distraction rods } \\
\text { (L1-5) }\end{array}$ \\
\hline 9 & 22 & $\begin{array}{l}\text { Hit by } \\
\text { barrel }\end{array}$ & T11-12 & Flex-dist. & T5 & Compression & $\begin{array}{l}\text { Compression rods } \\
\text { (T10-L1) }\end{array}$ \\
\hline 10 & 30 & MVA & T9 & Burst & $\mathrm{T} 12$ & Compression & Non-operative \\
\hline 11 & 20 & MVA & L4 & Burst & L1 & Compression & Non-operative \\
\hline 12 & 19 & MVA & Ll & Burst & $\mathrm{T} 8$ & Compression & $\begin{array}{l}\text { Distraction rods } \\
\text { (T10-L3) }\end{array}$ \\
\hline 13 & 49 & Fall & Ll & Burst & $\mathrm{T} 10$ & Compression & $\begin{array}{l}\text { Distraction rods } \\
\text { (T8-L4) }\end{array}$ \\
\hline
\end{tabular}

injuries, all located in the thoracic or lumbar spine, were a burst fracture in nine patients, a flexion-distraction injury in three, and a fracture-dislocation in one. The minor injury was a compression fracture in 10 patients (two occurring in the cervical spine), and one case each of a C5 teardrop fracture, a C2 spinous process fracture, and a C6-7 subluxation.

Three of the five patients with non-contiguous cervical fractures had an open reduction and internal fixation of their major thoracic or lumbar injury (Cases $1,2,4)$. In all three cases, follow-up radiographs demonstrated maintenance of the reduction achieved and healing of the fracture. All of the cervical injuries were treated non-operatively, and none of these injuries had progression of either deformity or displacement.

Four of the eight non-contiguous thoracic and lumbar injuries (Cases 8, 9, $12,13)$ had an open reduction and posterior Harrington instrumentation. In two patients (Cases 8 and 13), the instrumentation included all of the injured vertebrae and healing occurred uneventfully. In the remaining two patients (Cases 9 and 12), only the major fracture was instrumented and further collapse of the vertebral body occurred at the minor fracture site, resulting in a large gibbus deformity in one patient (Case 12). The case histories of these two patients are summarised below.

\section{Case 12}

A 19-year-old female was a passenger on a motorcycle that collided with an automobile. She suffered a closed right talus fracture-dislocation, a right acetabular fracture, a fracture of the sternum, and non-contiguous spine fractures 

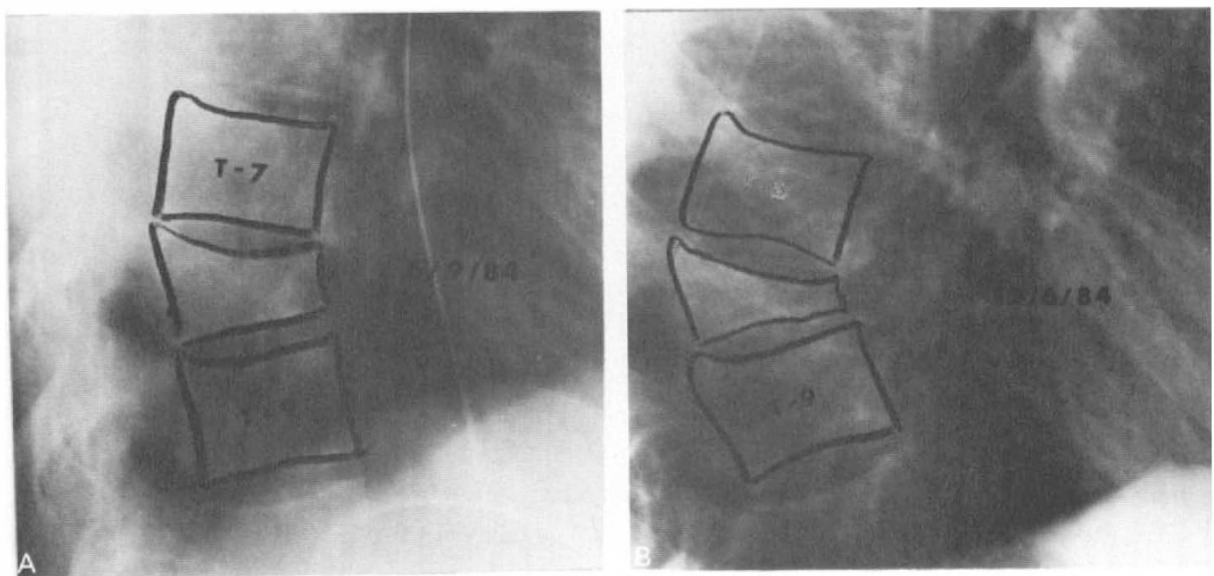

Figure 1a, 1b The initial lateral radiograph (Fig. 1a) of Case 12 demonstrating the noncontiguous, $\mathrm{T} 8$ compression fracture. A lateral radiogram obtained 6 months after the injury (Fig. 1b) demonstrates that anterior vertebral body compression had increased from 21 to $63^{\circ}{ }_{0}$, angle of deformity from 14 to $30^{\circ}$, and sagittal plane translation from 0 to $4 \mathrm{~mm}$.
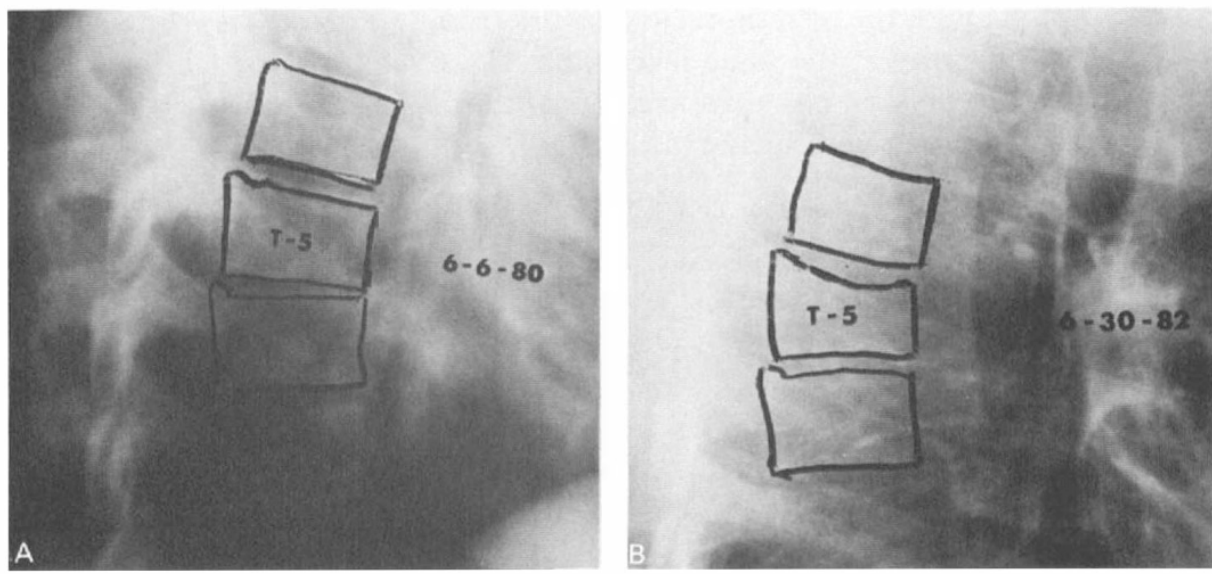

Figure 2a, 2b The initial lateral radiograph (Fig. 2a) of the non-contiguous, T5 compression fracture in Case 9. A lateral radiograph obtained 2 years after the injury (Fig. 2b) demonstrated progression of anterior vertebral body compression from 7 to $31^{\circ}{ }_{0}$, and an increase in angle of deformity from 33 to $44^{\circ}$.

consisting of an L1 burst fracture and a T8 compression fracture (Fig. 1a). There was a mild weakness in the left toe flexors and extensors, but sensation was intact. Within 24 hours of the injury, she had an open reduction of her L1 burst fracture with bilateral Harrington distraction rods and segmental interspinous process wiring that extended from the 10th thoracic to the $3 \mathrm{rd}$ lumbar vertebra. The patient had an uneventful postoperative course and at the time of discharge had a normal neurological examination.

At 6 months, the patient was asymptomatic and radiographs revealed the maintenance of reduction and healing of the L1 burst fracture. However, radiographs of the thoracic spine (Fig. 1b) demonstrated a significant progression of the kyphotic deformity at T8. Anterior vertebral body compression 
had increased from $21 \%$ to $63^{\circ}{ }_{\mathrm{o}}$, angle of deformity from $14^{\circ}$ to $30^{\circ}$, and sagittal plane translation from 0 to $4 \mathrm{~mm}$.

\section{Case 9}

A 22-year-old male was struck on the back by a 350 pound barrel in a farm accident. He sustained non-contiguous spine fractures consisting of a T5 compression fracture (Fig. 2a) and a T11-12 flexion-distraction injury. There were no other injuries. Neurological examination shortly after the injury revealed an absence of motor function and deep-tendon reflexes in both lower extremities, and anaesthesia to sensory testing in the perianal area. A closed reduction of the T11-12 flexion-distraction fracture was attempted in the emergency room, but was unsuccessful. The patient subsequently underwent an open reduction, posterior fusion, and internal fixation with bilateral Harrington compression rods that spanned the tenth thoracic to first lumbar vertebral laminae. Within 2 weeks, the patient had regained motor function in both lower extremities, but had failed to regain bladder function. Radiographs obtained 2 years after the injury (Fig. 2b) demonstrated progression of anterior vertebral body compression of the fifth thoracic vertebra from $7 \%$ to $31 \%$ and an increase in angle of deformity at the same level from $33^{\circ}$ to $44^{\circ}$. The patient is now $4 \frac{1}{2}$ years after the injury and has only occasional intermittent pain at the level of the fifth thoracic vertebra with heavy lifting.

\section{Discussion}

Previous reports have documented a $3 \cdot 2{ }^{\circ}$ o to $4 \cdot 5 \%$ incidence of non-contiguous spinal injuries and have noted that a delay in diagnosis of the minor level of injury is not uncommon. In this study, the incidence of non-contiguous fractures was $16.7 \%$. The higher incidence of non-contiguous fracture documented in our patient population may be due to the fact that our hospital is a major trauma centre for the state, and thus, an unusually high number of patients with multiple, severe injuries are flown in for treatment. The progression of the deformity at the 'minor' level of injury in the two patients that only had the major level instrumented may be due to the increased forces that occur at the vertebrae above and below the rigid instrumentation. When the vertebra adjacent to the instrumentation is normal, these stresses have little clinical importance. Should the instrumentation lie close to, but not include a vertebra which already is compromised, these increased forces may have a more deleterious effect and result in a progressive deformity.

From this study, we concluded that non-contiguous vertebral fractures are not uncommon. Therefore, patients with fractures at one level should have radiographic examination of their entire spine. If non-contiguous fractures are evident on the standard radiographs, all levels of injury should be thoroughly evaluated with computerised tomography. If the minor level is unstable or there is doubt concerning its stability, it should be included within the instrumentation. With Harrington instrumentation, this method of treatment may require instrumentation of very long segments of the spine and severely restrict motion. Thus, short segmental fusions and interpedicular screw fixation, or short 
fusions that only encompass the unstable segments and removal of the Harrington rods after the fusions are solid, may prevent deformities and enhance subsequent mobility of the spine.

\section{References}

BRADFORd DS, AKBaRnia BA, Winter RB, et al. 1977 Surgical stabilisation of fracture and fracture dislocations of the thoracic spine. Spine 2:185-196.

Calenoff L, Chessare JW, Rogers LF, et al. 1978 Multiple level spine injuries: Importance of early recognition. American fournal of Roentology 130:665-669.

Dickson JH, HARRINGTON PR, ERWIN WD 1978 Results of reduction and stabilisation of the severely fractured thoracic and lumbar spine. Fournal of Bone and foint Surgery 60A:799-805.

GRIFFITH HB, GLEAVE JRW, TAYLOR RG 1966 Changing patterns of fracture in the dorsal and lumbar spine. British Medical fournal 1:891-894. 